\title{
Virtual screening of synthesized thiazole derivatives for $M$. tuberculosis and dTDP-rhamnose inhibitors
}

\author{
Dighe Rajendra D.*, Bairagi Vinod A., Pathade Parag A., Sonawane Yogesh T \\ K.B.H.S.S Trust's Institute of Pharmacy, Tal. Malegaon, Dist. Nashik, M.S. -423105
}

\begin{abstract}
To determine antimycobacterium and dTDP rhamnose inhibitor activity of the synthesized azetidinone, thiazolidinone derivatives of thiazole, we studied different derivatives for the activity. One pot synthesis of 2-amino-4-methylthiazole-5-carboxylic acid ethyl ester has been carried out and synthesized different derivative compounds. Compounds were tested for antimicrobial activity against different strains of microorganism and antitubercular activity against M. tuberculosis H37Rv. Compounds 7c, 7d, 7i, 8d, 8e, 8g and 8h, were showed antimicrobial activity against Staphylococcus aureus, Escherichia coli, Pseudomonas aeruginosa, Salmonella typhosa using Gentamycin as standard, while 7b, 7e, 7f, 7i, 8b, 8e, 8f and $8 \mathrm{i}$ showed very strong antimycobacterial activity using rifampicine as a standard. Thiazole derivatives especially with carbonyl group scaffold inhibit an enzyme RmlC, which is an essential component for the biosynthesis of $d$ TDP-rhamnose and produce good antimycobacterium and antimicrobial activity.
\end{abstract}

Keywords: Thiazole, thiazolidinone derivatives, azetidinone derivative, well diffusion method, broth microdilution assay, antitubercular activity, antimicrobial activity.

Article Info: Received 02 Dec 2018; $\quad$ Review Completed 06 Jan 2019; $\quad$ Accepted 09 Jan 2019; Available online 15 Jan 2019

\section{Cite this article as:}

Dighe RD, Bairagi VA, Pathade PA, Sonawane YT, Virtual screening of synthesized thiazole derivatives for M. tuberculosis and $d$ TDP-rhamnose inhibitors, Journal of Drug Delivery and Therapeutics. 2019; 9(1):207-210 DOI: http://dx.doi.org/10.22270/jddt.v9i1.2324

*Address for Correspondence:

Dr. Dighe Rajendra D., K.B.H.S.S trust's institute of pharmacy, Malegaon-Camp, Malegaon, Dist- Nashik, Maharashtra-423105

\section{INTRODUCTION}

Microbial infections remain the major cause of death over the world. Emergence of multi-drug resistant to different infectious organisms like M. tuberculosis made the condition most alarming1, 2. Therefore, there is an urgent demand for a new class of antimicrobial agent with a different mode of action and it led medicinal chemists to explore a wide variety of chemical structures. A de novo structural design has demonstrated that the thiazole derivatives especially with carbonyl group scaffold inhibit an enzyme $R m I C$, which is an essential component for the biosynthesis of $d$ TDPrhamnose $^{3}$. While reports 4,5 are available stating emergence of thiazole as potent antibacterial agent. $\beta$-Lactams are the most successful antimicrobials ${ }^{6,7,8,9}$. Till recent days, unless microorganisms targeted, are not resistant. (By production of $\beta$-lactamase) Appreciation of these finding towards the development of novel antimicrobial agents, coupled with our program of drug design ${ }^{10,11}$. It was thought to club together two or three nuclei having different sites or mechanism of action. This initiated us constructing compounds containing both the thiazole, azetidinone \& thiazolidinone ring systems in the same matrix to serve as a new scaffold.

\section{MATERIAL AND METHODS}

Scheme (Figure 1) for synthesis of 2-amino-4methylthiazole-5-carboxylic acid ethyl ester (3) ${ }^{12}$ and its derivatives (4-8) ${ }^{10}, 11$. The various chemicals used in the synthesis of the titled compounds were purchased from, sigma-aldrich pvt ltd, spectrochem pvt ltd and S.D. fine chem pvt ltd. The nucleus and its derivatives were analyzed by different ways. The melting points were recorded on electrothermal apparatus and are uncorrected. ${ }^{1} \mathrm{H}$ NMR spectra on a Bruker Avance $300 \mathrm{MHz}$ instrument using $\mathrm{CDCl}_{3}$ as solvent using TMS as internal standard; the chemical shifts $(\delta)$ were reported in ppm with coupling constants $($ ) are given in Hz. Signal multiplicities were represented by $\mathrm{s}$ (singlet), d (doublet), t (triplet), ds (double singlet), dd (double doublet), $\mathrm{m}$ (multiplet) and bs (broad singlet). The purity of the compounds was checked on silica gel coated $\mathrm{Al}$ plates (Merck) 

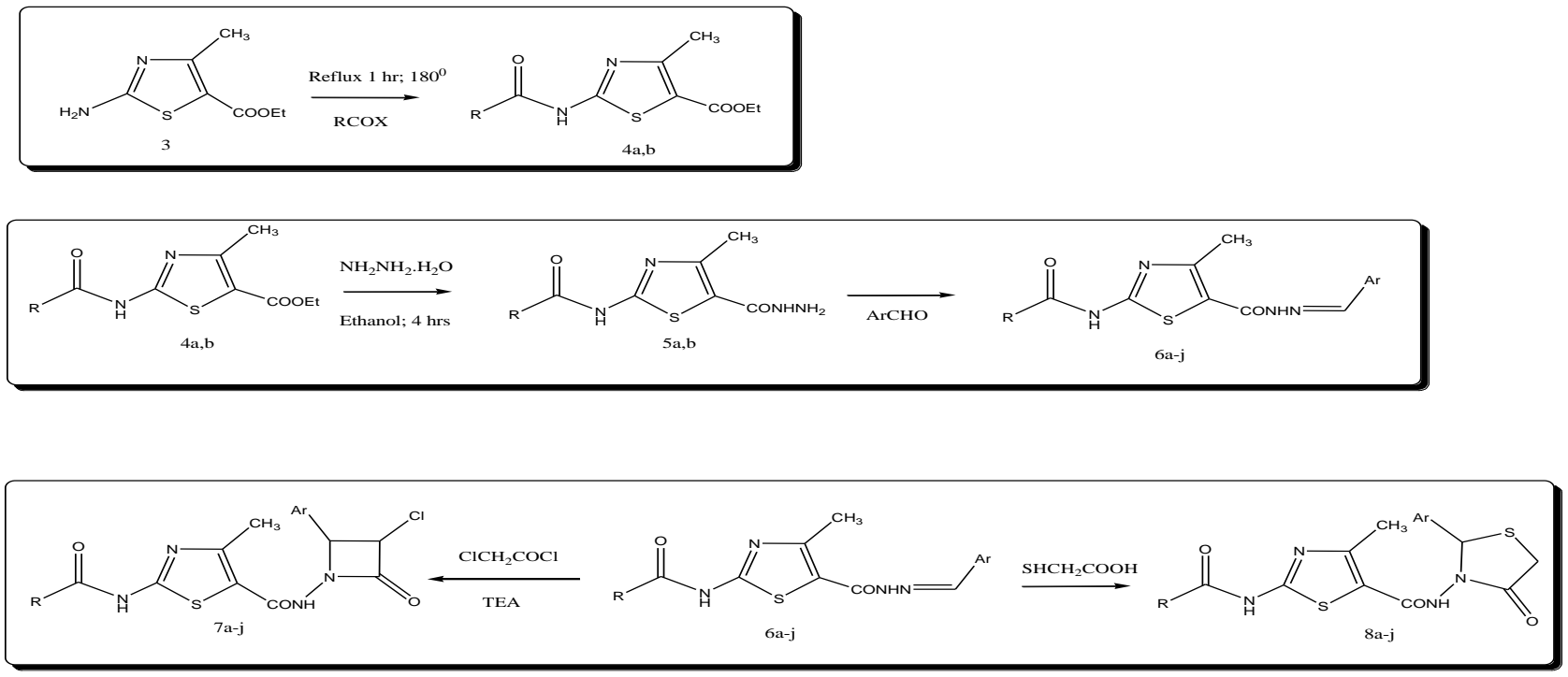

Figure 1: Scheme for synthesis of 2-amino-4-methylthiazole-5-carboxylic acid ethyl ester(3) and its derivatives(4-8)

\section{Synthesis of Ethyl-2-substitutedamido-4-methylthiazol-5- carboxylate (4).}

Ethyl-2-amino-4-methylthiazol-5-carboxylate (3) (1 mmol, $2 \mathrm{~g}$ ) was taken in a $50 \mathrm{~mL}$ round bottom flask. Acetic anhydride or benzoyl chloride $(1 \mathrm{mmol})$ was added to the above solution slowly with constant stirring. The mixture was then refluxed for $1 \mathrm{~h}$. The solution was poured in icecold water with vigorous stirring, to yield precipitate. The suspension was then heated to boiling and cooled under tap water. The product was filtered, dried and recrystallized by ethanol to get (4);

\section{Synthesis of 2-Substitutedamido-4-methylthiazol-5-} carboxylic acid hydrazide (5)

Ethyl-2-substitutedamido-4-methylthiazol-5-carboxylate (4) ( $6 \mathrm{mmol})$ and $98 \%$ hydrazine hydrate $(1.2 \mathrm{mmol})$ was taken in a round bottom flask and heated for five minutes. Ethanol was added to the above solution till the mixture becomes clear solution. Then the mixture was refluxed for $4 \mathrm{~h}$ on water bath maintaining the temperature between 70-75 9 C. The excess of alcohol was removed by distillation. On cooling, fine white precipitate of 2-substitutedamido-4methylthiazol-5-carboxylic acid hydrazide (5) was obtained. The product was washed with water, filtered and dried and recrystallized from water.

\section{Synthesis of N-[5-(arylidene-hydrazinocarbonyl)-4- methyl-thiazol-2-yl]-substituted-amide (6).}

2-substitutedamido-4-methylthiazol-5-carboxylic acid hydrazide (5) (1 mmol) and aryl aldehyde $(1 \mathrm{mmol})$ was taken in ethanol (15 mL), 3-4 drops of concentrated $\mathrm{H}_{2} \mathrm{SO}_{4}$ was added and refluxed for $2 \mathrm{~h}$. The reaction mixture was cooled and the solid separated was filtered, washed with cold ethanol, and recrystallized from ethanol to obtained $\mathrm{N}$ [5-(arylidene-hydrazinocarbonyl)-4-methyl-thiazol-2-yl]substituted-amide (6).

\section{Synthesis of 2-Substituted-amino-4-methyl-thiazol-5- carboxalic acid (3-chloro-2-oxo-4-aryl-azetidin-1-yl)- amide (7).}

$N$-[5-(arylidene-hydrazinocarbonyl)-4-methyl-thiazol-2-yl]substituted-amide (6) (1 mmol) was dissolved in $25 \mathrm{~mL} \mathrm{1,4-}$ dioxane. Triethylamine ( $1 \mathrm{mmol}, 1 \mathrm{~mL}$ ) was added drop wise with constant stirring to the solution, followed by similar addition of chloroacetyl chloride $(1 \mathrm{mmol}, 2 \mathrm{~mL})$. The mixture was then stirred for $30 \mathrm{~min}$ followed by refluxing for ISSN: 2250-1177
$5 \mathrm{~h}$. It was then cooled and filtered to remove insoluble salts. Excess of solvent was then distilled off. The concentrated solution was poured on crushed ice with vigorous stirring. The precipitate formed was filtered, washed with water and recrystallized by ethanol and water.

\section{Synthesis of 2-Substituted-amino-4-methyl-thiazol-5- carboxalic acid (4-oxo-2-aryl-thiazolidin-3-yl)-amide (8).}

$\mathrm{N}$-[5-(arylidene-hydrazinocarbonyl)-4-methyl-thiazol-2-yl]substituted-amide (6) (1 mmol) was dissolved in $20 \mathrm{~mL}$ anhydrous 1, 4-dioxane. Thioglycollic acid (1.5 mmol, $1.38 \mathrm{~g}$ ) was added slowly drop wise with stirring. A pinch of aluminium chloride was added and the mixture was then stirred for $30 \mathrm{~min}$ followed by refluxing for $6 \mathrm{~h}$. It was then cooled and filtered to remove insoluble salt. The concentrated solution was poured into aqueous saturated solution of $\mathrm{NaHCO}_{3}$ with stirring. The precipitate formed was filtered, washed with water and recrystallized by alcohol and water.

\section{Antitubercular activity}

Primary screening was conducted at $6.25 \mu \mathrm{g} \mathrm{mL}-1$ against $M$. tuberculosis H37Rv (ATCC 27294) in BACTEC 12B medium using a broth microdilution assay, the Microplate Alamar Blue Assay (MABA) ${ }^{13}$. Compounds exhibiting fluorescence were tested in the BACTEC 460 radiometric system ${ }^{14}$. Compounds showing more than $/ 95 \%$ inhibition in the primary screening were considered active and then re-tested at a lower concentrations against M. tuberculosis H37Rv in order to determine the actual MIC, using MABA. The MIC is defined as the lowest concentration effecting a reduction in fluorescence of $95 \%$ with respect to the controls. Rifampin (RMP) was used as the reference compound (RMP MIC $=/ 0.015-0.125 \mathrm{mg} \mathrm{mL}^{-1}$ ). We also have done cytotoxicity analysis of the above-synthesized compounds, using neutral red uptake by using Vero-C-1008 cell line at various concentrations $(6.25 \mu \mathrm{g} / \mathrm{mL}$ to $50 \mu \mathrm{g} / \mathrm{mL})$, none of them were found toxic. Hence the activities of the abovesynthesized compounds were not due to cytotoxicity.

\section{Antimicrobial activity}

Microbial strains- Staphylococcus aureus ATCC 23564, Escherichia coli ATCC35218, Pseudomonas aeruginosa ATCC 25619, Salmonella typhi ATCC 10749

The compounds listed in the table 3 were screened for the antimicrobial activity against different microorganisms using 
well diffusion method 15,16 , where $50 \mu \mathrm{M}$ and $100 \mu \mathrm{M}$ concentrations were taken for activity in nutrient agar medium. Chloroform was used as solvents and antibiotic Gentamycin was used as standard. The culture was kept for 24 hours. The nutrient agar medium, $20 \mathrm{~mL}$ was poured into the sterile petri dishes. To the solidified plates, wells were made using a sterile cork borer $10 \mathrm{~mm}$ in diameter. The 24 hour (at $24-28{ }^{\circ} \mathrm{C}$ ) subcultured bacteria was inoculated in the petri-plates, with a sterile cotton swab dipped in the nutrient broth medium. After inoculating, the compounds were dissolved separately with the chloroform solvent and poured into the wells with varying concentrations ranging from $50 \& 100 \mu \mathrm{M}$ using a micropipette. The plates were left over for 24 hours at $24-28{ }^{\circ} \mathrm{C}$. The antibiotic Gentamycin was used as a standard for comparative study. The percentage of inhibition was calculated by the formula; percent Inhibition $=$ Diameter of the inhibition zone $\mathrm{x} 100$

\section{RESULTS}

Table 1: MIC and growth inhibition of the compounds against M. tuberculosis H37Rv

\begin{tabular}{|c|c|c|c|c|}
\hline Comp & $\mathbf{R}$ & Ar & MIC $\left(\mu \mathrm{g} / \mathrm{mL}^{-1}\right)^{\mathrm{a}}$ & GI (\%)b \\
\hline $7 \mathrm{a}$ & $\mathrm{NHCOCH}_{3}$ & $-\mathrm{C}_{6} \mathrm{H}_{5}$ & $<6.25$ & ---- \\
\hline $7 b$ & $\mathrm{NHCOCH}_{3}$ & $-4-\mathrm{F}-\mathrm{C}_{6} \mathrm{H}_{4}$ & $<6.25$ & 100 \\
\hline $7 \mathrm{c}$ & $\mathrm{NHCOCH}_{3}$ & $-3,4,5-\mathrm{CH}_{3} \mathrm{O}-\mathrm{C}_{6} \mathrm{H}_{2}$ & $<6.25$ & ---- \\
\hline $7 \mathrm{~d}$ & $\mathrm{NHCOCH}_{3}$ & $-4-\left(\mathrm{CH}_{3}\right)_{2} \mathrm{~N}-\mathrm{C}_{6} \mathrm{H}_{4}$ & $<6.25$ & $-\cdots$ \\
\hline $7 \mathrm{e}$ & $\mathrm{NHCOCH}_{3}$ & $-2-\mathrm{F}-\mathrm{C}_{6} \mathrm{H}_{4}$ & $<6.25$ & 100 \\
\hline $7 \mathrm{f}$ & $\mathrm{NHCOC}_{6} \mathrm{H}_{5}$ & $-4-\mathrm{Cl}-\mathrm{C}_{6} \mathrm{H}_{4}$ & $<6.25$ & 96 \\
\hline $7 g$ & $\mathrm{NHCOC}_{6} \mathrm{H}_{5}$ & $-3-\mathrm{NO}_{2}-\mathrm{C}_{6} \mathrm{H}_{4}$ & $<6.25$ & $\begin{array}{ll}--- \\
\end{array}$ \\
\hline $7 \mathrm{~h}$ & $\mathrm{NHCOC}_{6} \mathrm{H}_{5}$ & $-4-\mathrm{OH}-\mathrm{C}_{6} \mathrm{H}_{4}$ & $<6.25$ & $-\cdots$ \\
\hline $7 \mathrm{i}$ & $\mathrm{NHCOC}_{6} \mathrm{H}_{5}$ & $-2-\mathrm{Cl}-\mathrm{C}_{6} \mathrm{H}_{4}$ & $<6.25$ & 98 \\
\hline $7 j$ & $\mathrm{NHCOC}_{6} \mathrm{H}_{5}$ & $-2-\mathrm{NO}_{2}-\mathrm{C}_{6} \mathrm{H}_{4}$ & $<6.25$ & ---- \\
\hline $8 \mathrm{a}$ & $\mathrm{NHCOCH}_{3}$ & $-\mathrm{C}_{6} \mathrm{H}_{5}$ & $<6.25$ & $-\cdots$ \\
\hline $8 \mathrm{~b}$ & $\mathrm{NHCOCH}_{3}$ & $-4-\mathrm{F}-\mathrm{C}_{6} \mathrm{H}_{4}$ & $<6.25$ & 98 \\
\hline $8 \mathrm{c}$ & $\mathrm{NHCOCH}_{3}$ & $-3,4,5-\mathrm{CH}_{3} \mathrm{O}-\mathrm{C}_{6} \mathrm{H}_{2}$ & $<6.25$ & $-\cdots$ \\
\hline $8 \mathrm{~d}$ & $\mathrm{NHCOCH}_{3}$ & $-4-\left(\mathrm{CH}_{3}\right)_{2} \mathrm{~N}-\mathrm{C}_{6} \mathrm{H}_{4}$ & $<6.25$ & $-\cdots$ \\
\hline $8 \mathrm{e}$ & $\mathrm{NHCOCH}_{3}$ & $-2-\mathrm{F}-\mathrm{C}_{6} \mathrm{H}_{4}$ & $<6.25$ & 100 \\
\hline $8 \mathrm{f}$ & $\mathrm{NHCOC}_{6} \mathrm{H}_{5}$ & $-4-\mathrm{Cl}-\mathrm{C}_{6} \mathrm{H}_{4}$ & $<6.25$ & 97 \\
\hline $8 g$ & $\mathrm{NHCOC}_{6} \mathrm{H}_{5}$ & $-3-\mathrm{NO}_{2}-\mathrm{C}_{6} \mathrm{H}_{4}$ & $<6.25$ & $\begin{array}{ll}--- \\
\end{array}$ \\
\hline $8 \mathrm{~h}$ & $\mathrm{NHCOC}_{6} \mathrm{H}_{5}$ & $-4-\mathrm{OH}-\mathrm{C}_{6} \mathrm{H}_{4}$ & $<6.25$ & $\begin{array}{ll}--- \\
\end{array}$ \\
\hline $8 \mathrm{i}$ & $\mathrm{NHCOC}_{6} \mathrm{H}_{5}$ & $-2-\mathrm{Cl}-\mathrm{C}_{6} \mathrm{H}_{4}$ & $<6.25$ & 97 \\
\hline $8 \mathrm{j}$ & $\mathrm{NHCOC}_{6} \mathrm{H}_{5}$ & $-2-\mathrm{NO}_{2}-\mathrm{C}_{6} \mathrm{H}_{4}$ & $<6.25$ & ---- \\
\hline
\end{tabular}

aMIC of rifampin: 0.015-0.125 $\mathrm{mg} \mathrm{mL}^{-1}$ versus M. tuberculosis $\mathrm{H} 37 \mathrm{Rv}$ ( $97 \%$ inhibition).

bGrowth inhibition of virulent H37 Rv strain of M. tuberculosis.

Table 2: Second level Actual minimum inhibitory concentration of the compounds.

\begin{tabular}{|l|l|l|l|}
\hline SN & $\mathbf{M I C}^{(\boldsymbol{\mu} \mathbf{M})^{\mathbf{a}}}$ & $\mathbf{S N}$ & $\mathbf{M I C}(\boldsymbol{\mu M})^{\mathbf{a}}$ \\
\hline $7 \mathrm{~b}$ & 6.25 & $8 \mathrm{~b}$ & 3.13 \\
\hline $7 \mathrm{e}$ & 1.56 & $8 \mathrm{e}$ & 6.25 \\
\hline $7 \mathrm{f}$ & 3.13 & $8 \mathrm{f}$ & 6.25 \\
\hline $7 \mathrm{i}$ & 0.39 & $8 \mathrm{i}$ & 0.78 \\
\hline
\end{tabular}

a Actual minimum inhibitory concentration (MABA assay).

Table 3: Antibacterial activity of the synthesized compounds.

\begin{tabular}{|l|l|l|l|l|l|l|l|l|l|}
\hline \multirow{2}{*}{ Comp. } & \multicolumn{4}{|c|}{ Organisms } & \multirow{2}{*}{ Comp. } & \multicolumn{4}{|c|}{ Organisms } \\
\cline { 2 - 7 } & Sa & Pa & Ec & St & & Sa & Pa & Ec & St \\
\hline $7 \mathrm{a}$ & 18 & 17 & 14 & 12 & $8 \mathrm{a}$ & 18 & 16 & 10 & 12 \\
\hline $7 \mathrm{~b}$ & 18 & 16 & 15 & 14 & $8 \mathrm{~b}$ & 20 & 16 & 10 & 10 \\
\hline $7 \mathrm{c}$ & 22 & 20 & 18 & 14 & $8 \mathrm{c}$ & 22 & 22 & 20 & 16 \\
\hline $7 \mathrm{~d}$ & 25 & 22 & 20 & 16 & $8 \mathrm{~d}$ & 26 & 24 & 22 & 18 \\
\hline $7 \mathrm{e}$ & 20 & 20 & 18 & 14 & $8 \mathrm{e}$ & 36 & 34 & 30 & 30 \\
\hline $7 \mathrm{f}$ & 16 & 16 & 20 & 16 & $8 \mathrm{f}$ & 24 & 22 & 20 & 18 \\
\hline $7 \mathrm{~g}$ & 16 & 10 & 10 & 18 & $8 \mathrm{~g}$ & 22 & 11 & 24 & 24 \\
\hline $7 \mathrm{~h}$ & 11 & 17 & 15 & 22 & $8 \mathrm{~h}$ & 22 & 22 & 20 & 20 \\
\hline $7 \mathrm{i}$ & 32 & 32 & 30 & 36 & $8 \mathrm{i}$ & 36 & 38 & 32 & 32 \\
\hline $7 \mathrm{j}$ & 16 & 16 & 12 & 12 & $8 \mathrm{j}$ & 16 & 16 & 12 & 14 \\
\hline Gent & 34 & 35 & 31 & 30 & Gent & 34 & 35 & 31 & 30 \\
\hline
\end{tabular}

Sa: Staphylococcus aureus, Ec: Escherichia coli, Pa: Pseudomonas aeruginosa, St: Salmonella typhosa, Gent: Gentamycin

\section{Antitubercular activity}

During the preliminary screening 20 compounds $7 \mathrm{a}-7 \mathrm{j}$ and 8a-8j were tested (Table 1) at $6.25 \mu \mathrm{g} / \mathrm{mL}$ concentration for their antimycobacterial activity, eight compounds $7 \mathrm{~b}, 7 \mathrm{e}, 7 \mathrm{f}$, $7 \mathrm{i}, 8 \mathrm{~b}, 8 \mathrm{e}, 8 \mathrm{f}$ and $8 \mathrm{i}$ have exhibited more than $96 \%$ inhibition at this concentration while other compounds exhibited less than $90 \%$ inhibition at the same concentration. SAR of the synthesized compounds suggests that most of these compounds are very much similar to each other, differing in the substitutions on the aryl ring. And it can be seen that compounds having halogen are more potent than other. On 
the other hand, in secondary screening (Table-2), only 7i, 7e and $8 \mathrm{i}$ were found to have promising antimycobacterial activity. Other compounds are not as active as the earlier ones. Although we have not been able to substantially enhance the activity of these compounds in the present study, the data presented here are encouraging and deserve further investigation.

\section{Antimicrobial activity}

It has been found that all the compounds tested showed broad spectrum of inhibitory properties. From the antibacterial screening it was observed that all the compounds exhibited activity against all the organisms employed. Looking at the structure activity relationship, marked inhibition in bacteria was observed in the compounds $7 \mathrm{i}, 8 \mathrm{i}$ and $8 \mathrm{e}$ whereas $7 \mathrm{c}, 7 \mathrm{~d}, 8 \mathrm{~d}, 8 \mathrm{f}, 8 \mathrm{~g}$ and $8 \mathrm{~h}$ have shown moderate activity and others showed least activity (Table 3).

\section{DISCUSSION}

2-Amino-4-methyl-thiazole-5-carboxylic acid ethyl ester (3) was synthesized by cyclization of 2-bromo-ethylacetoacetate with thiourea. The internal bromination of ethylacetoacetate was achieved by treatment with N-bromosuccinamide. Free radical reaction generated by benzoyl peroxide was used initiator. The reactive amino group was then protected, either by acetylation or benzoylation process to yield 2-substitutedamino-4-methyl-thiazole-5-carboxylic acid ethyl ester $(4 a, 4 b)$. Chemical transformation of compound $(4 a, 4 b)$ to hydrazide derivative $(5 a, 5 b)$ was achieved. The free amino group of hydrazide was condensed to schiff's base (6a-6j), by reacting with arylaldehydes in ethanol, which on treatment with mercaptoacetic acid and chloroacetyl chloride gave thiazolidinone (8a-8j) and azetidinone (7a-7j) derivatives respectively. Compounds $7 \mathrm{c}, 7 \mathrm{~d}, 7 \mathrm{i}, 8 \mathrm{~d}, 8 \mathrm{e}, 8 \mathrm{~g}$ and $8 \mathrm{~h}$ have shown antimicrobial activity against microorganism, while $7 \mathrm{~b}, 7 \mathrm{e}, 7 \mathrm{f}, 7 \mathrm{i}, 8 \mathrm{~b}, 8 \mathrm{e}, 8 \mathrm{f}$ and $8 \mathrm{i}$ have shown very strong antimycobacterial activity. Recent studies have pointed to the essential nature of rhamnose in some cell walls and capsules. L-Rhamnose is a 6-deoxyhexose that is found in a variety of different glycol-conjugates in the cell walls of pathogenic bacteria. The precursor of L-rhamnose is dTDP-L-rhamnose, which is synthesised from glucose- 1-phosphate and deoxythymidine triphosphate (dTTP) via a pathway requiring enzymes. Significantly this pathway does not exist in humans and all four enzymes therefore represent potential therapeutic targets. dTDP-D-glucose 4,6-dehydratase (RmlB; EC 4.2.1.46) is the second enzyme in the dTDP-L-rhamnose biosynthetic pathway. The immediate source of rhamnose in carbohydrate polymers is dTDP-L-rhamnose. The other enantiomer, D-rhamnose, is primarily utilised by Pseudomonas aeruginosa. A de novo structural design has demonstrated that the thiazole derivatives especially with carbonyl group scaffold inhibit an enzyme RmlC, which is an essential component for the biosynthesis of $d$ TDP-rhamnose. While, reports are available stating emergence of thiazole as potent antibacterial agent. The structure has been refined to a crystallographic R-factor of $20.4 \%$ and an R-free value of $24.9 \%$ with good stereochemistry. (By production of $\beta$ lactamase) Appreciation of these finding towards the development of novel antimicrobial agents, coupled with our program of drug design, it was thought to club together two or three nuclei having different sites or mechanism of action. Hence the synthesized and identified compounds possess antimycobacterium potential as well as are dTDP-rhamnose inhibitors.

\section{CONCLUSION}

Thiazole derivatives especially with carbonyl group scaffold inhibit an enzyme RmlC, which is an essential component for the biosynthesis of $d$ TDP-rhamnose and produce good antimycobacterium and antimicrobial activity.

\section{ACKNOWLEDGEMENT}

Authors are thankful to Dr. Shinde Shashikant, Associate Vice President and Dr. Khaire Jitendra, Hr Head Mylan Lab. LTD , Nashik for providing necessary facilities to carry out this research work. Authors are thankful to Dr. Das Ashitosh, CSIR, IIIM Jammu for help during biological activity of the compounds.

\section{REFERENCES}

1. Ania AE, Idokob J, Dalyopc YB, Pitmangd SL, Drug resistance profile of mycobacterium tuberculosis isolates from pulmonary tuberculosis patients in Jos, Nigeria, Transactions of the Royal Society of Tropical Medicine and Hygiene, 2009; 103:67-71.

2. Said HA, Abdel GS, Morlock G, Cooksey RC, Molecular identification of mutations associated with anti-tuberculosis drug resistance among strains of mycobacterium tuberculosis, International Journal of Infectious Diseases, 2009; 13(6):673-678.

3. Babaoghe K, Page MA, Johns VC, Naismith JH, Lee RE, Novel inhibitors of an emerging target in mycobacterium tuberculosis; substituted thiazolidinones as inhibitors of dTDP-rhamnose synthesis, Bioorganic \& Medicinal Chemistry Letters, 2003; 13(19):3227-3230.

4. Khalil AM, Berghot MA, Gouda MA, Synthesis and antibacterial activity of some new thiazole and thiophene derivatives, European Journal of Medicinal Chemistry, 2009; 44(11):4434-4440.

5. Lamotte J, Dive G, Ghuysen JM, Conformational analysis of $\beta$ and $\gamma$ lactam antibiotics, European Journal of Medicinal Chemistry, 1991; 26(1):43-50.

6. Arnoldi A, Grasso S, Meinardi G, Merlini L, Synthesis and antifungal activity of simple $\beta$ lactams, European Journal of Medicinal Chemistry, 1988; 23(2):149-154

7. Jacqueline MB, Ruth L, Fabien DM, Jean MF, Synthesis and biological evaluation of new C (4) heterofunctionalized monocyclic $\beta$-lactams derived from penicillin G, European Journal of Medicinal Chemistry, 1988; 23(6):149-154

8. Luis J, Nunez V, Juan S, Measurement of interaction parameters between glutathione and $\beta$-lactam antibiotics: a polarographic approach, European Journal of Medicinal Chemistry, 1988; 23(6):573-575.

9. Wang Y, Lambert P, Zhao L, Wang D, Synthesis \& antibacterial activity of dual-action agents of a $\beta$-lactum antibiotic with cytotoxic agent mitozolomide or temozolomide, European Journal of Medicinal Chemistry, 2002; 37(4):323-332.

10. Shiradkar MR, Shivaprasad HN, Microwave assisted synthesis of novel azetidin-2-one and thiazolidi-4-one derivatives of triazolyl thiophene, Asian Journal of Chemistry, 2006; 18(1):331-338.

11. Shiradkar MR, Murahari KK, Reddy BH, Synthesis of new Sderivatives of clubbed triazolyl thiazole as anti-mycobacterium tuberculosis agents, Bioorganic \& Medicinal Chemistry, 2007; 15:3997-4008.

12. Dighe RD, Shiradkar MR, Rohom SS, Dighe PD, Microwave Assisted Synthesis and Evaluation of Thiazole Derivatives as M. tuberculosis and Antimicrobial Activity, International Journal of Drug Design and Discovery, 2011; 2 (2):464-463.

13. Daisy JV, Paramasivan CN, Evaluation of microplate alamar blue assay for drug susceptibility testing of Mycobacterium avium complex isolates, Diagnostic Microbiology and Infectious Disease, 2004; 49:179-182.

14. Clark BI, Lowell SY, Radiometric in vitro susceptibility testing of mycobacterium tuberculosis, The Antimicrobic Newsletter, 1986; $3(8): 55-62$.

15. NCCLS: Reference method for broth dilution antifungal susceptibility testing of yeasts; Approved standard. $2^{\text {nd }}$ ed. Pune: 2002. NCCLS document M27-A2.

16. Rautenbach $M$, du Toit EA, A sensitive standardised micro-gel well diffusion assay for the determination of antimicrobial activity, Journal of Microbiological Methods, 2000; 42:159-165. 